\title{
110th Anniversary: Distribution coefficients of furfural and 5- hydroxymethylfurfural in hydrophobic deep eutectic solvent + water systems: experiments and perturbed-chain statistical associating fluid theory predictions
}

Citation for published version (APA):

Dietz, C. H. J. T., Gallucci, F., van Sint Annaland, M., Held, C., \& Kroon, M. C. (2019). 110th Anniversary:

Distribution coefficients of furfural and 5-hydroxymethylfurfural in hydrophobic deep eutectic solvent + water systems: experiments and perturbed-chain statistical associating fluid theory predictions. Industrial and Engineering Chemistry Research, 58(10), 4240-4247. https://doi.org/10.1021/acs.iecr.8b06234

\section{Document license: \\ TAVERNE}

DOI:

10.1021/acs.iecr.8b06234

Document status and date:

Published: $13 / 03 / 2019$

\section{Document Version:}

Publisher's PDF, also known as Version of Record (includes final page, issue and volume numbers)

\section{Please check the document version of this publication:}

- A submitted manuscript is the version of the article upon submission and before peer-review. There can be important differences between the submitted version and the official published version of record. People interested in the research are advised to contact the author for the final version of the publication, or visit the $\mathrm{DOI}$ to the publisher's website.

- The final author version and the galley proof are versions of the publication after peer review.

- The final published version features the final layout of the paper including the volume, issue and page numbers.

Link to publication

\footnotetext{
General rights

- You may freely distribute the URL identifying the publication in the public portal. follow below link for the End User Agreement:

www.tue.nl/taverne

\author{
Take down policy \\ If you believe that this document breaches copyright please contact us at: \\ openaccess@tue.nl \\ providing details and we will investigate your claim.
}

Copyright and moral rights for the publications made accessible in the public portal are retained by the authors and/or other copyright owners and it is a condition of accessing publications that users recognise and abide by the legal requirements associated with these rights.

- Users may download and print one copy of any publication from the public portal for the purpose of private study or research.

- You may not further distribute the material or use it for any profit-making activity or commercial gain

If the publication is distributed under the terms of Article 25fa of the Dutch Copyright Act, indicated by the "Taverne" license above, please 


\title{
110th Anniversary: Distribution Coefficients of Furfural and 5-Hydroxymethylfurfural in Hydrophobic Deep Eutectic Solvent + Water Systems: Experiments and Perturbed-Chain Statistical Associating Fluid Theory Predictions
}

\author{
Carin H. J. T. Dietz, ${ }^{\dagger,}$ Fausto Gallucci, ${ }^{\dagger}$ Martin van Sint Annaland, ${ }^{\ddagger}$ Christoph Held, ${ }^{*}$, \\ and Maaike C. Kroon*,\|, $\perp_{\odot}$
}

\begin{abstract}
${ }^{\dagger}$ Inorganic Membranes and Membrane Reactors, Department of Chemical Engineering and Chemistry, Eindhoven University of Technology, P.O. Box 513, 5600 MB Eindhoven, Netherlands

${ }^{\ddagger}$ Chemical Process Intensification, Department of Chemical Engineering and Chemistry, Eindhoven University of Technology, P.O. Box 513, 5600 MB Eindhoven, Netherlands

${ }^{\S}$ Laboratory of Thermodynamics, Department of Biochemical and Chemical Engineering, TU Dortmund University, Emil-Figge-Straße 70, 44227 Dortmund, Germany

"Chemical Engineering Department, Khalifa University of Science and Technology, P.O. Box 127788, Abu Dhabi, United Arab Emirates

${ }^{\perp}$ Center for Catalysis and Separation, Khalifa University of Science and Technology, P.O. Box 127788, Abu Dhabi, United Arab Emirates
\end{abstract}

\section{Supporting Information}

ABSTRACT: Furfural (FF) and 5-hydroxymethylfurfural (HMF) are intermediates for many products, such as monomers for bioplastics, and can be obtained from various renewable resources. The isolation of these sugarderived molecules from aqueous solutions is one of the main challenges in biorefinery processes. In the work described in this paper, the separation of FF and HMF from aqueous phases is carried out with hydrophobic deep eutectic solvents (DESs) as new extracting agents. Distribution coefficients of FF and HMF in 10 different hydrophobic DES + water systems have been measured and compared to that of the benchmark extracting agent (toluene). The dependence of the distribution coefficients on the presence of sugars in the system has also been investigated. The hydrophobic DESs were found to selectively extract FF and HMF from aqueous solutions without any coextraction or precipitation of sugars. Finally, the distribution coefficients have been successfully predicted with PC-SAFT (perturbed-chain statistical associating fluid theory) without the need to fit any parameter to the measured distribution coefficients.

\section{INTRODUCTION}

In recent years, biomass has received increasing attention, both as an energy source and as a renewable raw material. ${ }^{1}$ The sugar polymers in biomass, i.e., cellulose and hemicellulose, can be hydrolyzed to free sugar monomers (glucose and fructose), which can be further converted into different platform chemicals. For example, furfural (FF) and 5-hydroxymethylfurfural (HMF) can be obtained by acid hydrolysis of these sugar monomers. ${ }^{2-4} \mathrm{FF}$ and HMF are the most interesting sugar-derived chemicals, because they are intermediates from which many other products can be made, such as monomers for bioplastics. ${ }^{5,6}$ Moreover, they can be obtained from various renewable agricultural resources and residues from forest products. $^{7-9}$

Purifications, separations, and solvent recoveries determine the economic feasibility of the FF and HMF production

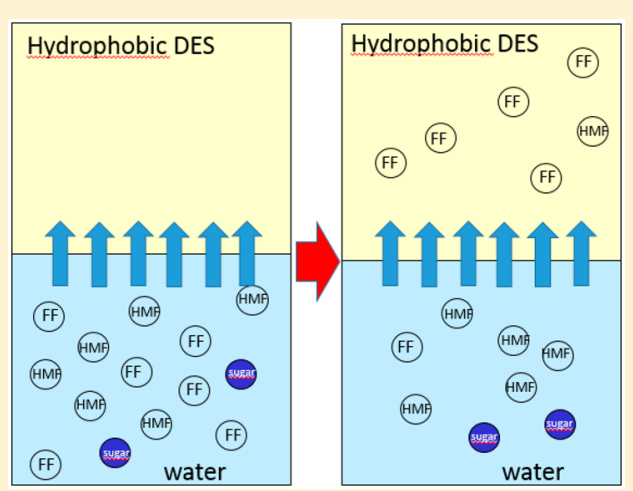

processes. ${ }^{10}$ The isolation of these sugar-derived chemicals is the main challenge in their production. ${ }^{11}$ Until now, steam stripping and liquid-liquid extraction with toluene have been the most commonly applied isolation methods. ${ }^{12-14}$ Steam stripping is highly energy-intensive. The effectiveness of liquid-liquid extraction depends on the solvent selection. For a rational solvent selection, the following properties should be considered: distribution ratio, selectivity, density, recoverability, environmental impact, viscosity, toxicity, flammability, and thermal and chemical stability. Extraction with toluene causes problems in the solvent recovery step due to the

Received: December 17, 2018

Revised: January 29, 2019

Accepted: February 19, 2019

Published: February 19, 2019 
Table 1. Chemicals Used, Including Purity (As Provided by the Supplier), Source, CAS Registry Number, and Melting Point $\left(T_{\mathrm{m}}\right)$

\begin{tabular}{|c|c|c|c|c|}
\hline name & purity (wt\%) & source & CAS no. & $T_{\mathrm{m}}(\mathrm{K})$ \\
\hline atropine & $>99$ & Sigma-Aldrich & $51-55-8$ & 391 \\
\hline decanoic acid & $>98$ & Sigma-Aldrich & $334-48-5$ & $300-305$ \\
\hline D-fructose & $>99$ & Sigma-Aldrich & $57-48-7$ & $373-377$ \\
\hline dodecanoic acid & $>98$ & Sigma-Aldrich & $143-07-7$ & $316-318$ \\
\hline furfural & $>99$ & Sigma-Aldrich & $98-01-1$ & 237 \\
\hline glucose & $>99.5$ & Sigma-Aldrich & $50-99-7$ & $423-425$ \\
\hline 5-hydroxymethylfurfural & $\geq 99$ & Sigma-Aldrich & $67-47-0$ & $301-307$ \\
\hline$n$-tetraoctylammonium bromide & $\sim 98$ & Sigma-Aldrich & $14866-33-2$ & $368-371$ \\
\hline thymol & $>99$ & TCI Chemicals & $89-83-8$ & $322-325$ \\
\hline menthol & $>99$ & Sigma-Aldrich & $98-78-1$ & 304 \\
\hline lidocaine & $>99$ & Sigma-Aldrich & $137-58-6$ & $339-342$ \\
\hline
\end{tabular}

formation of a heterogeneous azeotrope between toluene and water. $^{15,16}$ Therefore, a lot of research is dedicated to the search for alternative extracting agents.

Recently, various deep eutectic solvents (DESs) were evaluated for their extraction performance for sugar-derived molecules, like FF and HMF from aqueous solutions. ${ }^{17}$ Also, DES-impregnated supported liquid membranes (SLMs) were investigated for selective separation of FF and HMF. ${ }^{18}$ DESs are mixtures of at least one hydrogen bond acceptor (HBA) and one hydrogen bond donor (HBD). ${ }^{19,20}$ When mixed in the proper molar ratio, they show a large decrease in melting point compared to the initial compounds. ${ }^{21}$ DESs are often assumed to be ionic liquid analogues, as they have similar properties to ionic liquids, e.g., low vapor pressure and tunability. ${ }^{1}$ Specifically, hydrophobic DESs ${ }^{21}$ were found to be promising extracting agents for FF and HFM from aqueous solutions. ${ }^{19}$ However, to the best of our knowledge, distribution coefficients of FF and HMF in hydrophobic DES/water systems have not yet been reported in the literature.

Moreover, studies predicting the solubilities of FF and HMF in DESs are completely absent. Until now, only $\mathrm{CO}_{2}$ solubilities in both hydrophilic and hydrophobic DESs have been modeled successfully using perturbed-chain statistical associating fluid theory (PC-SAFT). ${ }^{22,23}$ Two different modeling approaches for the DESs were compared in those works: (i) the "pseudo-pure" component approach, whereby the DES (even though it is a mixture) is considered as one component, and (ii) the individual-component approach, whereby both DES constituents are explicitly taken into account. $^{24}$ The pure-component PC-SAFT parameters for the individual-component approach of room-temperature solids can be accessed by thermodynamic data (water activity, density) of aqueous mixtures containing one of the DES constituents. However, measuring such data is very difficult and might not provide sufficient input to fit the parameters for very hydrophobic (water-insoluble) DES constituents. ${ }^{25}$ Therefore, the individual-component approach is not a suitable modeling approach for the hydrophobic DESs studied in this work. Instead, the "pseudo-pure" component modeling approach is more meaningful, and this is applied in this work. The main drawback of this very straightforward modeling approach is that new PC-SAFT parameters are required for each new composition of the DES constituents.

In this paper we present for the first time the distribution coefficients of FF and HMF in 10 hydrophobic DES-water systems and compare them to the benchmark solvent, toluene. First, we have selected one DES (decanoic acid:tetraoctyl- ammonium bromide in the molar ratio $2: 1$ ) to study the effects of the DES:water ratio, the starting concentration of FF and HMF, the addition of impurities (e.g., sugars), the temperature, and the $\mathrm{pH}$ value on the distribution coefficient. This DES is known for its high selectivity for FF/HMF over sugars, ${ }^{17}$ and so it was used to select suitable extraction conditions. Thereafter, the solubilities of FF, HMF, and glucose were measured in 10 different hydrophobic DESs. Also, the distribution coefficients of FF and HMF for these 10 DESs were measured at the selected extraction conditions and compared with predictions made with PC-SAFT. The parameters for the hydrophobic DESs were adjusted compared to our previous work by additional fitting to experimental volatility data (instead of correlation to density data only). ${ }^{26}$

\section{EXPERIMENTAL SECTION}

Chemicals. Table 1 presents information on all the chemicals used in this work, including their purity, source, and melting point. All chemicals were used without any further purification.

DESs Preparation. The 10 different hydrophobic DESs prepared in this work, including their hydrogen bond donors (HBDs) and hydrogen bond acceptors (HBAs) and the ratio between the HBD and HBA, are listed in Table 2. Both solids (HBD and HBA) were weighed in the desired molar ratio in a round-bottom flask, mixed, and heated in an oil bath at $313 \mathrm{~K}$ for $2 \mathrm{~h}$ to obtain a liquid, the DES, which stayed liquid after

Table 2. DESs Prepared in This Work, Including Their Hydrogen Bond Donor (HBD), Hydrogen Bond Acceptor (HBA), HBD:HBA Ratio, and Abbreviation

\begin{tabular}{clcl} 
HBD & \multicolumn{1}{c}{ HBA } & $\begin{array}{c}\text { molar } \\
\text { ratio }\end{array}$ & $\begin{array}{l}\text { abbreviation } \\
\text { decanoic acid }\end{array}$ \\
$\begin{array}{c}n \text {-tetraoctylammonium } \\
\text { bromide }\end{array}$ & $2: 1$ & deca-n8888Br \\
decanoic acid & thymol & $1: 1$ & deca-thy \\
decanoic acid & lidocaine & $2: 1$ & deca-lid 2:1 \\
decanoic acid & lidocaine & $3: 1$ & deca-lid $3: 1$ \\
decanoic acid & lidocaine & $4: 1$ & deca-lid $4: 1$ \\
decanoic acid & menthol & $1: 1$ & deca-men \\
thymol & lidocaine & $2: 1$ & thy-lid \\
decanoic acid & atropine & $2: 1$ & deca-atr \\
dodecanoic & atropine & $2: 1$ & dode-atr \\
acid & lidocaine & $2: 1$ & dode-lid \\
dodecanoic & & &
\end{tabular}


cooling to room temperature to produce an approximate amount of $25 \mathrm{~g}$ of DES.

Solubility Measurements. The solubilities of FF, HMF, and glucose in the 10 selected DESs were measured (in duplicate) by the cloud point method with a standard uncertainty of $u(w)=0.005$. In a vial, a 5 g portion of each DES was weighed and heated to 303,323 , and $373 \mathrm{~K}$ (with a standard uncertainty in temperature of $u(T)=0.2 \mathrm{~K})$, respectively. A small amount of FF, HMF, or glucose was added, and only if the small amount was dissolved after $2 \mathrm{~h}$, the experiment was continued by adding a little more the FF, HMF or glucose, until full saturation was achieved.

Extraction Measurements. The extraction of FF and HMF with the 10 hydrophobic DESs was measured using different starting concentrations of FF and HMF in water (i.e., $0.25,0.50,1.0,1.5,3.0$, and $5.0 \mathrm{wt} \%)$. First, $5 \mathrm{~g}$ portions of these aqueous solutions were put into a centrifuge tube of 50 $\mathrm{mL}$, and different amounts of DES (different solvent-to-feed ratios) were added. After mixing in a shake machine (IKA KS 4000i) during the applied shaking time (i.e., 10, 30, 60, and $300 \mathrm{~s}$ and $1 \mathrm{~h}$ ) at $500 \mathrm{rpm}$ at the selected temperature (i.e., 298,323 , and $353 \mathrm{~K}$ ), the tubes were centrifuged (Sigma 2$16 \mathrm{KL}$ ) for $30 \mathrm{~min}$ with a speed of $8000 \mathrm{rpm}$ at the selected temperature in order to separate the DES from the aqueous phase. A sample of the aqueous phase was taken $( \pm 1 \mathrm{~mL})$ and analyzed using high-performance liquid chromatography (HPLC).

HPLC Analyses. The concentrations of FF, HMF, glucose, and fructose were measured by HPLC using an Agilent Technologies 1200 series instrument (Agilent Technologies, Santa Clara, USA), equipped with a multiple-wavelength detector (G1365D), an evaporated light scattering detector (ELDS Grace Alltech), and a thermostatic autosampler. Separation was carried out at $298 \mathrm{~K}( \pm 1 \mathrm{~K})$; the mobile phase composition was acetonitrile:water $(98: 2 \mathrm{v} \% / \mathrm{v} \%)$ with a $1 \mathrm{~mL} \mathrm{m^{-1 }}$ flow rate and injection volume of $5 \mu \mathrm{L}$, using a Jordi GEL DVB polyamine column $(250 \mathrm{~mm} \times 4.6 \mathrm{~mm}$, cat. no. 17010, Jordi Labs LLC, Bellingham).

PC-SAFT Modeling. Gross and Sadowski ${ }^{27,28}$ introduced PC-SAFT as an advanced equation of state that combines physical soundness and engineering needs. PC-SAFT is based on statistical thermodynamics, developed by Barker and Henderson. $^{29,30}$ PC-SAFT is a perturbation theory that accounts for perturbations from a hard-chain reference system by association and dispersive forces. It calculates the residual Helmholtz energy $a^{\text {res }}$ (difference between the total molar Helmholtz energy and the Helmholtz energy of an ideal gas) as the sum of the free-energy contributions caused by hard-chain repulsion $a^{\text {hc }}$, dispersion forces $a^{\text {disp }}$, and site-site specific hydrogen-bonding interactions $a^{\text {assoc }}$ (eq 1 ):

$$
a^{\text {res }}=a^{\text {hc }}+a^{\text {disp }}+a^{\text {assoc }}
$$

In PC-SAFT, pure components can be described using five pure-component parameters: (i) the segment number $\left(m_{\text {seg, } i}\right)$, (ii) the temperature-independent segment diameter $\left(\sigma_{i}\right)$, (iii) the dispersion-energy parameter $\left(u_{i} / k_{\mathrm{B}}\right)$, (iv) the associationenergy parameter $\left(\varepsilon^{\mathrm{A} i \mathrm{~B} i} / k_{\mathrm{B}}\right)$, and (v) the effective-volume parameter of an association site $\left(\kappa^{\mathrm{AiBi}}\right)$. The pure-component parameters for water, FF, and HMF and the "pseudo-pure" component parameters for the hydrophobic DESs are already available in the literature ${ }^{26}$ and are shown in the Supporting Information, Table S1. It should be mentioned that the DESs are treated as "pseudo-pure" components (instead of mixtures), as it was found previously to be the most convenient strategy for modeling the distribution coefficients of hydrophilic DESs. ${ }^{12,26}$

The availability of $a^{\text {res }}$ allows determination of fugacity coefficients by derivations with respect to density and mole fraction. In this work, fugacity coefficients were used to calculate activity coefficients $\gamma_{i}$ (eq 2) by the ratio of the fugacity coefficient of component $i$ in the mixture, $\varphi_{i}$, to the fugacity coefficient of pure component $i, \varphi_{0 i}$, at the same pressure and temperature:

$$
\gamma_{i}=\frac{\varphi_{i}\left(T, p, x_{i}\right)}{\varphi_{0 i}\left(T, p, x_{i}=1\right)}
$$

At infinite dilution, the distribution coefficient $K^{x}(x$ refers to mole-fraction scale) for component $i$ between two phases can be predicted with PC-SAFT. For this purpose, the activity coefficients of component $i$ were predicted at infinite dilution in the two phases. In this work, these two phases are the equilibrated DES-rich (DES) and DES-poor aqueous (aq) phases, and the corresponding activity coefficients at infinite dilution are denoted as $\gamma_{i}^{\mathrm{DES} \infty}$ and $\gamma_{i}^{\text {aq } \infty}$, respectively. The composition of the equilibrated phases of the binary DES + water system has to be known to model $\gamma_{i}^{\mathrm{DES} \infty} \gamma_{i}^{\text {aq } \infty}$. These compositions were experimentally available from previous works. ${ }^{31}$ The ratio of both quantities yields the distribution coefficient of component $i$ at infinite dilution $K_{i}^{x, \infty}$ (eq 3):

$$
K_{i}^{x, \infty}=\frac{\gamma_{i}^{\mathrm{DES} \infty}}{\gamma_{i}^{\mathrm{aq} \infty}}
$$

The use of this $K_{i}^{x, \infty}$ value is only reasonable given that component $i$ is present at very low concentrations. This assumption is reasonable in this work. As $K_{i}^{x, \infty}$ is a mole-based quantity, conversion to mass-based units is required, which can be done using the molar masses of water, $M_{\mathrm{H}_{2} \mathrm{O}}$, and the DES, $M_{\mathrm{DES}}$ :

$$
K_{i}^{w, \infty}=\frac{\gamma^{\mathrm{DES} \infty}}{\gamma^{\mathrm{aq} \infty}} \frac{M_{\mathrm{DES}}}{M_{\mathrm{H}_{2} \mathrm{O}}}
$$

For more information regarding the PC-SAFT model, the corresponding formulas, the mixing rules, and the parametrization, the interested reader is referred to previous works. $^{26-28}$

\section{RESULTS AND DISCUSSION}

Distribution coefficients $(K)$ for FF and HMF in various DES + water systems were experimentally determined via eq 5 :

$$
K=\frac{w_{\mathrm{O}}}{w_{\mathrm{A}}}
$$

where $w_{\mathrm{O}}$ and $w_{\mathrm{A}}$ stand for the weight fraction of FF or HMF in the organic and aqueous phases, respectively. It should be noted that these values correspond to the $K_{i}^{w}$ values calculated using the PC-SAFT model (eq 4).

Extraction Optimization. The extraction of the pure components FF and HMF using one selected DES (deca$\mathrm{n} 8888 \mathrm{Br}(2: 1))$ was performed in order to study the effects of the DES:water ratio, the starting concentration of FF and HMF, the addition of impurities (e.g., sugars), the temperatures, and the $\mathrm{pH}$ values on the distribution coefficients. First, the extraction of FF and HMF at a temperature of $298 \mathrm{~K}$ and 
at different solvent-to-feed ratios (DES: water) was carried out by bringing both phases into contact via shaking during 5,10 , 20,30 , and $60 \mathrm{~min}$. The results for the obtained distribution coefficients are presented in Table S2 in the Supporting Information. From this table it can be noticed that the extraction is already complete after 5 min of shaking time. In the rest of this work, a shaking time of $2 \mathrm{~h}$ was selected (as usually applied in literature), and this means that equilibrium was guaranteed. Next, three different starting concentrations of pure FF and HMF $(0.25,0.5$, and $1.5 \mathrm{wt} \%)$ were extracted with the selected DES (deca-n8888Br) at three different solvent-to-feed ratios (DES:water $=1: 1,1: 2$, and 1:10, which are equivalent to water mole fractions of $0.500,0.667$, and 0.909 , respectively). The results for the obtained distribution coefficients are shown in Table 3. The following two

Table 3. Distribution Coefficients for Extraction of the Pure Components FF and HMF at $298 \mathrm{~K}$ and 1.01 bar Using deca-n8888Br as Extracting Agent at Different Solvent-toFeed (DES:Water) Ratios and Different Starting Concentrations $^{a}$

\begin{tabular}{cccc} 
& & \multicolumn{2}{c}{$K$} \\
\cline { 3 - 4 } starting concn of FF/HMF (wt\%) & DES:water ratio & FF & HMF \\
\hline 1.5 & $10: 10$ & 4.6 & 1.6 \\
& $5: 10$ & 4.2 & 2.3 \\
& $1: 10$ & 2.5 & 1.8 \\
& & & \\
& $10: 10$ & 4.6 & 1.6 \\
& $5: 10$ & 3.6 & 1.1 \\
& $1: 10$ & 2.2 & 1.8 \\
0.25 & & & \\
& $10: 10$ & 5.3 & 1.7 \\
& $5: 10$ & 4.3 & 2.2 \\
& $1: 10$ & 2.3 & 1.9
\end{tabular}

${ }^{a}$ Standard uncertainties are $u(T)=1 \mathrm{~K}, u(p)=0.03$ bar and $u(K)=$ 0.5 .

observations can be made: (i) the starting concentration of the solute does not have a significant influence on the distribution coefficients of FF and HMF, and (ii) the solventto-feed ratio has a large influence on the distribution coefficient-the higher the better, especially for FF. This is a general trend that is commonly observed in many systems. ${ }^{16}$ Of course, the ratio between the DES and the water is also changing when the amount of FF or HMF in the feed is changing, but this effect will be very small, as the concentrations of FF and HMF in the feed are very low. This is the reason why the feed concentration does not have a significant influence on the measured distribution coefficients. The difference in distribution coefficients between FF and HMF can be explained by the difference in hydrophobicities of the two components. HMF (completely water-miscible) is much more hydrophilic than FF (maximum water solubility at $298 \mathrm{~K}$ is only $77 \mathrm{~g} \cdot \mathrm{L}^{-1}$, as stated by the supplier), and therefore the hydrophobic DESs are more selective for FF.

It is interesting to investigate the influence of other (side)components on the obtained distribution coefficients of FF and HMF. First, the influence of a mixture of FF and HMF (in different mixing ratios) on the distribution coefficients $K_{\mathrm{FF}}$ and $K_{\mathrm{HMF}}$ was studied. Therefore, three different starting solutions with both components at different concentrations (mixture 1 consisted of $1.5 \mathrm{wt} \% \mathrm{FF}$ and $1.5 \mathrm{wt} \% \mathrm{HMF}$; mixture 2 consisted of $0.5 \mathrm{wt} \% \mathrm{FF}$ and $1.5 \mathrm{wt} \% \mathrm{HMF}$; mixture 3 consisted of $1.5 \mathrm{wt} \% \mathrm{FF}$ and $0.5 \mathrm{wt} \% \mathrm{HMF}$ ) were prepared. The results are shown in Table 4.

Table 4. Distribution Coefficients Obtained by Extraction with deca-n8888Br at $298 \mathrm{~K}$ and 1.01 bar from Different Starting Mixtures of FF and HMF at Different Solvent-toFeed (DES:Water) Ratios ${ }^{a}$

\begin{tabular}{|c|c|c|c|}
\hline \multirow[b]{2}{*}{ feed composition } & \multirow[b]{2}{*}{ DES:water ratio } & \multicolumn{2}{|c|}{$K$} \\
\hline & & $\mathrm{FF}$ & HMF \\
\hline \multirow[t]{3}{*}{ mixture $1(1.5 w t \%$ FF $+1.5 w t \%$ HMF $)$} & $10: 10$ & 4.3 & 2.4 \\
\hline & $5: 10$ & 4.0 & 1.9 \\
\hline & $1: 10$ & 2.5 & 1.7 \\
\hline \multirow[t]{3}{*}{ mixture $2(0.5$ wt $\%$ FF +1.5 wt $\%$ HMF $)$} & $10: 10$ & 4.0 & 1.8 \\
\hline & $5: 10$ & 4.3 & 1.6 \\
\hline & $1: 10$ & 3.2 & 1.2 \\
\hline \multirow[t]{3}{*}{ mixture $3(1.5$ wt $\% \mathrm{FF}+0.5 \mathrm{wt} \% \mathrm{HMF})$} & $10: 10$ & 4.0 & 1.6 \\
\hline & $5: 10$ & 4.3 & 2.0 \\
\hline & $1: 10$ & 2.3 & 1.9 \\
\hline
\end{tabular}

From Tables 3 and 4, it can be concluded that $K_{\mathrm{FF}}$ and $K_{\mathrm{HMF}}$ were almost not influenced by addition of the other component, so cross-component interactions were negligible, which is reasonable at the very low concentrations of FF and HMF.

Usually, FF and HMF are produced from biomass-derived sugars. Thus, sugars are often present in reaction mixtures containing FF and HMF. Therefore, the influence of the addition of both glucose and fructose on $K_{\mathrm{FF}}$ and $K_{\mathrm{HMF}}$ was also investigated using the following multi-component starting concentrations: $1.0 \mathrm{wt} \% \mathrm{FF}+1.0 \mathrm{wt} \% \mathrm{HMF}+1.0 \mathrm{wt} \%$ glucose $+1.0 \mathrm{wt} \%$ fructose. The results for the obtained distribution coefficients at two different solvent-to-feed ratios are listed in Table 5.

Table 5. Distribution Coefficients Obtained by Extraction with deca-n8888Br at $298 \mathrm{~K}$ and 1.01 bar from a MultiComponent Starting Solution (FF + HMF + Glucose + Fructose) at Different Solvent-to-Feed Ratios ${ }^{a}$

\begin{tabular}{|c|c|c|c|c|c|}
\hline \multirow[b]{2}{*}{ feed composition } & \multirow[b]{2}{*}{$\begin{array}{l}\text { DES:water } \\
\text { ratio }\end{array}$} & \multicolumn{4}{|c|}{$K$} \\
\hline & & FF & HMF & glucose & fructose \\
\hline $\begin{array}{l}\text { FF }(1 w t \%)+\text { HMF }(1 w t \%)+ \\
\text { glucose }(1 w t \%)+ \\
\text { fructose }(1 w t \%)\end{array}$ & $10: 10$ & 4.3 & 1.4 & 0 & 0 \\
\hline $\begin{array}{l}\text { FF }(1 \mathrm{wt} \%)+\mathrm{HMF}(1 \mathrm{wt} \%)+ \\
\text { glucose }(1 \mathrm{wt} \%)+ \\
\text { fructose }(1 \mathrm{wt} \%)\end{array}$ & $05: 10$ & 4.1 & 1.6 & 0 & 0 \\
\hline
\end{tabular}

When comparing the results in Table 5 (presence of sugars) with the values in Table 4 (absence of sugars), it can be noticed that also the addition of glucose and fructose to the starting solution hardly influences the obtained values for $K_{\mathrm{FF}}$ and $K_{\mathrm{HMF}}$. Moreover, both sugars are not obtained in the extract phase. This means that the extraction is highly selective for FF and HMF over sugars. Thus, during the production of FF and HMF from biomass-derived sugars, the sugars will stay 
in the reaction mixture, while only FF and HMF are selectively extracted into the DES phase.

The measured distribution coefficients for FF and HMF using the DES deca-n $8888 \mathrm{Br}$ have been compared with those obtained using toluene as extracting agent. Therefore, the extraction of FF and HMF from a 1 wt $\%$ FF +1 wt $\%$ HMF starting mixture at a temperature of $298 \mathrm{~K}$ was carried out using different solvent-to-feed ratios (10:10, 8:10, 5:10, 4:10. $3: 10,2: 10$, and 1:10), where both the DES and toluene were compared as solvents. The results for the obtained distribution coefficients are shown in Table 6. The measured distribution

Table 6. Distribution Coefficients Obtained by Extraction with deca-n8888Br and Toluene at $298 \mathrm{~K}$ and 1.01 bar from a Starting Solution Consisting of $1 \mathrm{wt} \% \mathrm{FF}+1 \mathrm{wt} \% \mathrm{HMF}$ at Different Solvent-to-Feed Ratios ${ }^{a}$

\begin{tabular}{cccccc} 
& \multicolumn{2}{c}{$\begin{array}{c}K(\text { solvent }= \\
\text { deca-n8888Br })\end{array}$} & & \multicolumn{2}{c}{$K($ solvent $=$ toluene $)$} \\
\cline { 2 - 3 } \cline { 5 - 6 } DES:water ratio & FF & HMF & & FF & HMF \\
10:10 & 5.7 & 2.3 & & 5.0 & 0.2 \\
$8: 10$ & 4.7 & 1.9 & & 4.1 & 0.1 \\
$5: 10$ & 4.9 & 2.0 & & 3.8 & 0.1 \\
$4: 10$ & 3.8 & 1.6 & & 3.8 & 0.1 \\
$3: 10$ & 3.9 & 1.5 & & 3.6 & 0.1 \\
$2: 10$ & 3.9 & 1.7 & & 3.7 & 0.1 \\
$1: 10$ & 3.1 & 1.4 & & 3.5 & 0.1
\end{tabular}

${ }^{a}$ Standard uncertainties are $u(T)=1 \mathrm{~K}, u(p)=0.03$ bar, $u(K)=0.5$.

coefficients for FF using both solvents (deca-n8888Br or toluene) are comparable, with slightly higher values for the DES. However, the obtained distribution coefficients for HMF are much higher using the DES compared to the benchmark toluene or methyl isobutyl ketone (MIBK, $\left.K_{\mathrm{HMF}}=1.0\right) .{ }^{33}$ This suggests that the DES is a better extracting agent for HMF compared to toluene, most likely due to its higher polarity. Again, as expected, it is observed that higher solvent-to-feed ratios result in higher distribution coefficients.

In biorefinery processes, the reaction of xylose to FF usually takes place at high temperatures and low $\mathrm{pH}$ values. Therefore, the influences of a temperature increase and a $\mathrm{pH}$ decrease on the distribution coefficients of FF and HMF have also been studied. The results for the obtained distribution coefficients at three different temperatures $(298,323$, and $353 \mathrm{~K}$ ) and two different $\mathrm{pH}$ values (7 and 2 ) are presented in Table 7 . It can be noted that both the temperature and the $\mathrm{pH}$ do not have a significant influence on the extraction of both FF and HMF.

Table 7. Distribution Coefficients Obtained by Extraction with deca-n8888Br at Different Temperatures (298, 323, and $353 \mathrm{~K}$ ) and $\mathrm{pH}$ Values (7 and 2) at $\mathbf{1 . 0 1}$ bar from a Starting Solution Consisting of $1 \mathrm{wt} \%$ FF $+1 \mathrm{wt} \% \mathrm{HMF}$ at Different Solvent-to-Feed Ratios (1:1 and 1:2) ${ }^{a}$

\begin{tabular}{|c|c|c|c|c|c|c|c|}
\hline & \multirow{2}{*}{$\frac{\text { ratio }-}{\text { temp - }}$} & \multicolumn{3}{|c|}{$1: 1$} & \multicolumn{3}{|c|}{$1: 2$} \\
\hline & & $298 \mathrm{~K}$ & $323 \mathrm{~K}$ & $353 \mathrm{~K}$ & $298 \mathrm{~K}$ & $323 \mathrm{~K}$ & $353 \mathrm{~K}$ \\
\hline \multirow[t]{2}{*}{$\mathrm{FF}$} & $\mathrm{pH} 7$ & 3.0 & 3.8 & 3.6 & 5.6 & 5.4 & 4.2 \\
\hline & $\mathrm{pH} 2$ & 3.3 & 4.0 & 3.8 & 4.8 & 4.7 & 5.1 \\
\hline \multirow[t]{2}{*}{ HMF } & $\mathrm{pH} 7$ & 1.4 & 1.7 & 1.5 & 2.4 & 2.3 & 1.6 \\
\hline & $\mathrm{pH} 2$ & 1.5 & 1.8 & 1.6 & 2.5 & 1.9 & 2.0 \\
\hline
\end{tabular}

${ }^{a}$ Standard uncertainties are $u(T)=1 \mathrm{~K}, u(p)=0.03$ bar, $u(K)=0.5$.
This can be explained by the fact that the polarity of the DES phase is not significantly affected by a change in either temperature or $\mathrm{pH}$.

In conclusion, the only factor having a significant effect on the distribution coefficients of both FF and HMF in the selected DES is the solvent-to-feed ratio, and the distribution coefficients hardly depend on the feed composition, extraction time (beyond $5 \mathrm{~min}$ ), temperature, and $\mathrm{pH}$ value. It is suspected that the interaction between the FF or HMF and the DES (i.e., the activity coefficient of FF or HMF in the DES) is the most important factor determining the observed distribution ratios, and not the mutual solubilities between DES and water. Any co-extraction of water (more occurring at lower solvent-to-feed ratios) cannot explain the observed higher distribution coefficients of the more hydrophilic HMF at higher solvent-to-feed ratios.

Extraction of FF and HMF Using 10 Different Hydrophobic DESs. Next, the extraction of FF and HMF in 10 different hydrophobic DESs is investigated. The solubilities of FF, HMF, and glucose in these 10 different $\mathrm{DESs}^{32}$ at 298, 323, and $353 \mathrm{~K}$ were determined first. The results are presented in Table 8 . It should be noted that the

Table 8. Solubilities (in Weight Fraction, $w_{i}$ ) of FF, HMF, and Glucose in 10 Different DESs at 298, 323, and $353 \mathrm{~K}$ and 1.01 bar (Same Reported Values for Solubilities Are Achieved at the Three Temperatures $)^{a}$

\begin{tabular}{llll}
\multicolumn{1}{c}{ DES } & $\begin{array}{c}\text { FF miscibility } \\
(\%)^{b}\end{array}$ & $\begin{array}{c}\text { HMF solubility } \\
(\%)^{c}\end{array}$ & $\begin{array}{c}\text { glucose solubility } \\
(\%)\end{array}$ \\
deca-n8888Br & $\mathrm{m}$ & $\mathrm{s}$ & 0.10 \\
deca-thy & $\mathrm{m}$ & $\mathrm{s}^{*}$ & 0.10 \\
deca-men & $\mathrm{m}$ & 0.50 & 0.10 \\
deca-atr & $\mathrm{m}$ & 0.10 & 0.10 \\
deca-lid 2:1 & $\mathrm{m}$ & $\mathrm{s}$ & 0.10 \\
deca-lid 3:1 & $\mathrm{m}$ & $\mathrm{s}$ & 0.10 \\
deca-lid 4:1 & $\mathrm{m}$ & $\mathrm{s} *$ & 0.10 \\
dode-atr & $\mathrm{m}$ & $\mathrm{s}$ & 0.10 \\
dode-lid & $\mathrm{m}$ & $\mathrm{s} *$ & 0.10 \\
thy-lid & $\mathrm{m}$ & $\mathrm{s}$ & 0.10
\end{tabular}

${ }^{a}$ Standard uncertainties are $u(w)=0.005, u(T)=0.2 \mathrm{~K}$, and $u(p)=$ 0.03 bar. ${ }^{b} \mathrm{~m}=$ completely miscible, no heterogeneous regions. ${ }^{c} \mathrm{~s}=$ completely soluble, no precipitates; $\mathrm{s}^{*}=$ crystallizes after cooling to room temperature.

solubility data involve solid solubilities for HMF and glucose; however, for FF the stated solubilities are, in fact, liquid miscibilities (as this compound is a liquid at the temperatures applied, see Table 1).

It was observed that the temperature does not have any influence on the solubility of FF, HMF, and glucose in the DESs. In fact, exactly the same values are obtained for the solubilities at 298,323 , and $353 \mathrm{~K}$. The same behavior was found previously for other DESs in literature. ${ }^{17} \mathrm{FF}$ is completely miscible with all 10 DESs, while glucose is nearly insoluble in all 10 DESs (only $0.1 \%$ of the glucose dissolves in the DESs). The solubility of HMF depends on the choice of the DES. HMF is fully soluble in five hydrophobic DESs (deca$\mathrm{N} 8888 \mathrm{Br}$, deca-lid 2:1, deca-lid 3:1, dode-atr, and thy-lid), while it is not fully soluble (or crystallizes after cooling back to room temperature) in the other five DESs. The fact that glucose is nearly insoluble in all DESs while they are much better solvents for FF and HMF is beneficial for industrial 
applications. When the DESs are applied as extracting agents, they will selectively remove the FF and HMF from the reaction mixture with sugars. It is expected that DESs showing the highest solubilities for FF and HMF will be the most promising extracting agents.

Subsequently, the 10 DESs were applied as extracting agents for the removal of FF and HMF from aqueous solutions, and the data were compared to those obtained with the benchmark extracting agent toluene. The obtained distribution coefficients for FF and HMF using a solvent-to-feed ratio (DES: water) of $1: 1$, a starting concentration of pure FF or pure HMF of $1 \mathrm{wt}$ $\%$, a shaking time of $2 \mathrm{~h}$, and a shaking speed of $500 \mathrm{rpm}$ at $298 \mathrm{~K}$ and 1.01 bar are reported in Table S3 in the Supporting Information. The results are also graphically presented in Figure 1. From this figure, it can be concluded that the DESs

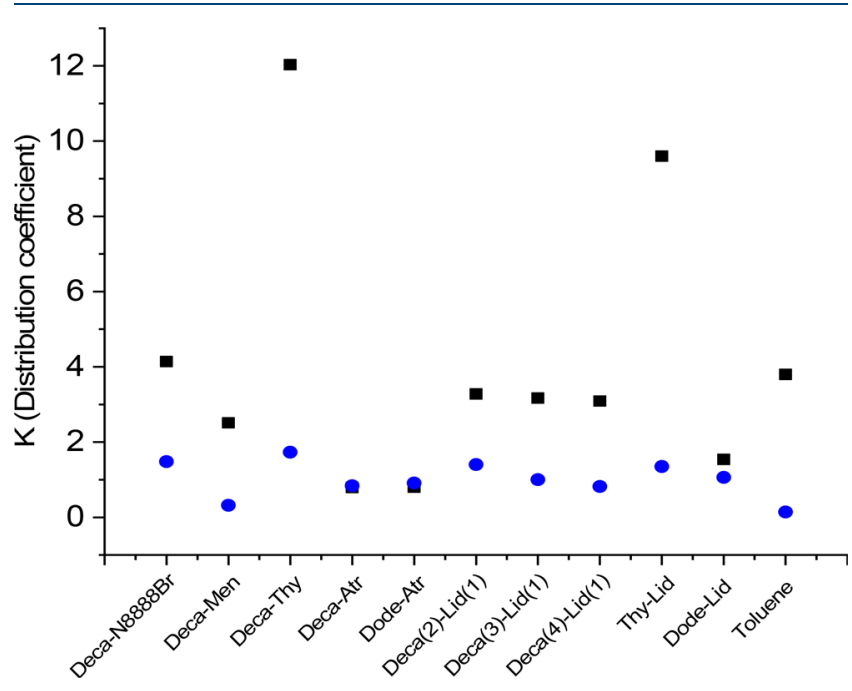

Figure 1. Distribution coefficients of FF (black square) and HMF (blue circle) in 10 different DESs and toluene, with solvent-to-feed ratio 1:10, shaking time $2 \mathrm{~h}$, shaking speed $500 \mathrm{rpm}$ at $298 \mathrm{~K}$ and 1.01 bar, and starting concentration $1 \mathrm{wt} \%$ of HMF or FF.

deca-thy and thy-lid outperform the benchmark solvent regarding the extraction of $\mathrm{FF}$, while deca-n $8888 \mathrm{Br}$, deca-lid 2:1, deca-lid 3:1, and deca-lid 4:1 show a similar performance compared to toluene. The other four DESs show worse performance. All DESs show better extraction of HMF compared to toluene. The explanation is that the DESs are all less hydrophobic than toluene. Remarkably, the DESs showing the highest solubilities for FF and HMF (Table 8) were not always the best extracting agents. In fact, the obtained distribution coefficient data do not seem to be correlated with the measured solubility data. This is most probably caused by the fact that the distribution coefficients depend on both the interaction of the FF and HMF with (one of) the DES' constituents and with water, while the solubilities were measured in a water-free system.

Other relations for the observed trends in the distribution coefficients were also investigated. For example, for the 10 different DESs, the Kamlet-Taft parameters were measured. These parameters are reported in Table S4 of the Supporting Information. However, there was no correlation between any of the three Kamlet-Taft parameters and the distribution coefficient, a finding that coincides with previous observations. ${ }^{23}$ It was also found that the starting concentrationss of FF $(0.1,0.2,0.3,0.4,0.5,0.6,0.7,0.8,0.9,1.0,3.0$, and $5.0 \mathrm{wt}$
$\%)$ and HMF $(0.1,0.2,0.3,0.4,0.5,0.6,0.7,0.8,0.9,1.0,10$, and $20 \mathrm{wt} \%)$ did not have a significant influence on the obtained distribution coefficients (see Tables S5 and S6 in the Supporting Information).

The recovery of FF and HMF from the DES, which is very important for a full techno-economical evaluation, was not investigated in this work but will be addressed in a separate future study. Specifically, vacuum distillation and the use of DES impregnated supported liquid membranes are currently being investigated as promising recovery methods.

PC-SAFT Modeling. PC-SAFT was applied to estimate the distribution coefficients at infinite dilution of FF and HMF in ternary DES + water + FF/HMF LLE systems. The results can be found in Tables S7 and S8 of the Supporting Information. These results are based on PC-SAFT pure-component parameters for the DESs, water, FF, and HMF. These are listed in Table S1 in the Supporting Information.

Figure 2 shows the comparison between the experimentally obtained FF distribution coefficients and the ones calculated

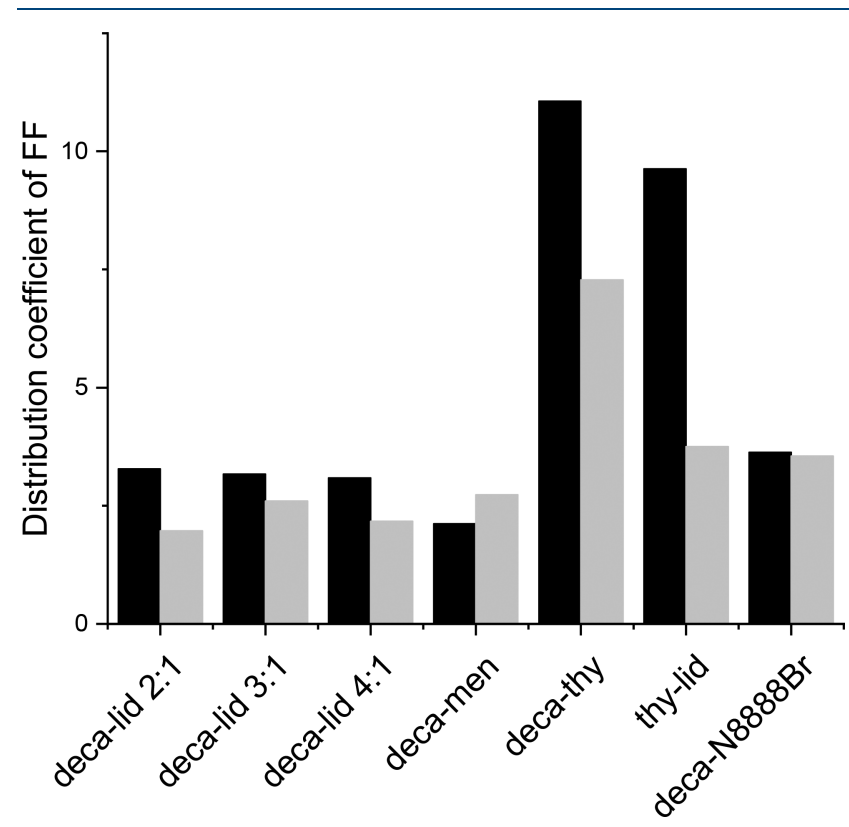

Figure 2. Distribution coefficient of FF between DES phase and aqueous phase in ternary systems (DES $\left.+\mathrm{H}_{2} \mathrm{O}+\mathrm{FF}\right)$. Black bars represent experimental data and gray bars PC-SAFT predictions using parameters from Table $\mathrm{S} 1$ in the Supporting Information $\left(k_{\mathrm{DES} \text {-water }}=\right.$ $0)$.

using PC-SAFT in a purely predictive mode (i.e., the three binary interaction parameters $k_{i j}$ of the pairs DES-water, DES-FF, and water-FF were set to zero). It can be noticed that the PC-SAFT predictions are qualitatively correct (i.e., showing comparable trends as experimentally observed). That is, PC-SAFT allows predicting a priori in which DES the highest distribution coefficients can be found for FF. These results further cross-validate the experimental findings from Figure 1, in which the two DESs deca-thy and thy-lid were found to outperform the benchmark extracting agent toluene.

PC-SAFT was not able to quantitatively predict the experimental values when all binary interaction parameters were set to zero. PC-SAFT systematically underestimated the distribution coefficients of HMF slightly. Thus, two binary interaction parameters $k_{i j}$ (for the binary DES + water system, and for the binary DES + HMF system) were introduced to 
account for the interaction of the DES with HMF and water. This allowed much more quantitative PC-SAFT predictions. Figure 3 shows the comparison between the experimentally

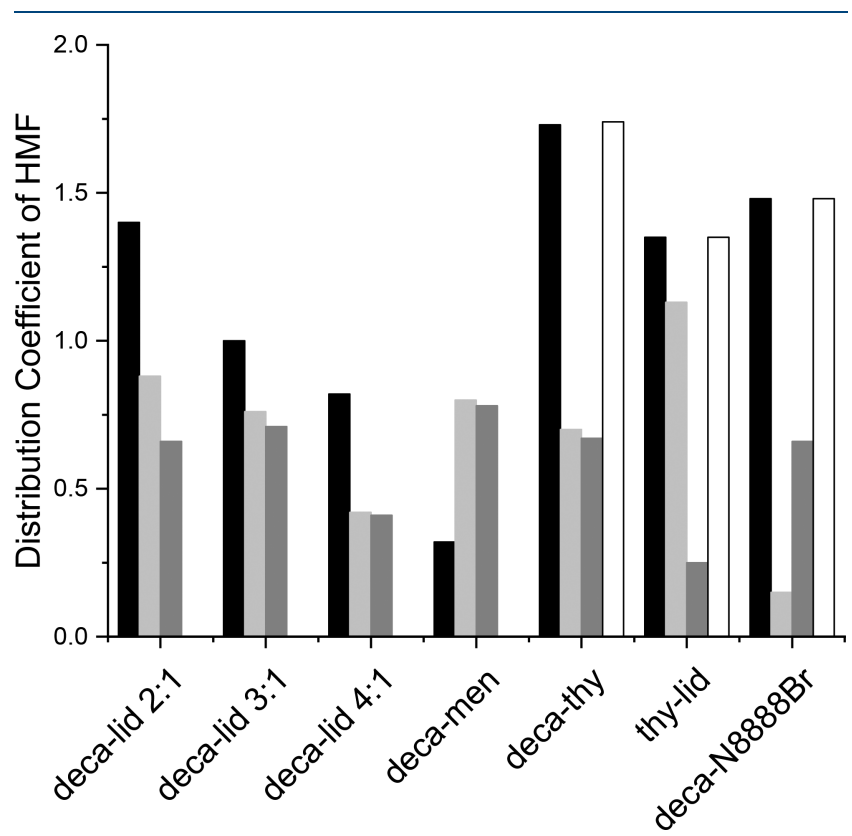

Figure 3. Distribution coefficient of HMF between the DES phase and the aqueous phase in the system (DES/ $\left.\mathrm{H}_{2} \mathrm{O} / \mathrm{HMF}\right)$. Black bars represent experimental data, light gray bars represent PC-SAFT predictions with $k_{\mathrm{DES} \text {-water }}=0$, dark gray bars represent PC-SAFT predictions with $k_{\mathrm{DES} \text {-water }} \neq 0$, and white bars represent PC-SAFT predictions using $k_{\mathrm{DES} \text {-water }} \neq 0$ and $k_{\mathrm{DES}: \mathrm{HMF}} \neq 0$. The latter were adjusted to solubility data; i.e., they are independent of any experimental $K$ value. The PC-SAFT parameters are listed in Tables S1 and S9 in the Supporting Information.

obtained HMF distribution coefficients and the so-obtained PC-SAFT calculated values. Nevertheless, these results are still predictive in the sense that no parameter was adjusted to experimental distribution coefficient data or any other data of the ternary water + DES + FF (HMF) systems under investigation. That is, all binary parameters were fitted to experimental data of binary systems only, i.e., LLE of water + DES and solubility data of HMF in DES; all these parameters were available already in the literature. ${ }^{34}$ Concluding from the results in Figures 2 and 3, $k_{i j}$ values between DES and water are not crucial for quantitative PC-SAFT modeling results, whereas the $k_{i j}$ between the goal component (HMF) and the DES is the decisive parameter that guarantees quantitatively correct predictions.

Thus, PC-SAFT was able to qualitatively predict the distribution coefficients of FF and HMF in ternary DES + water + FF/HMF LLE systems, although in some cases binary interaction parameters were required to make the predictions quantitatively correct. It should be noted that all DESs were treated as "pseudo-pure" components in this study. It is expected that binary interaction parameters may not need to be introduced in the case that the DESs are treated as mixtures of HBA and HBD.

\section{CONCLUSIONS}

The influence of the feed composition, temperature, $\mathrm{pH}$, and solvent-to-feed ratio on the distribution coefficients of FF and HMF in the selected DES (deca-n8888Br) + water system was investigated. Only the solvent-to-feed ratio was found to have a significant effect on the distribution coefficient; the other variables did not have a significant effect. Thereafter, the distribution ratios of FF and HMF in 10 different hydrophobic DESs were measured at the optimized conditions. All hydrophobic DESs show much better extraction of HMF compared to the benchmark solvent toluene. The DESs decathy and thy-lid perform excellently for the extraction of FF, while deca-n $8888 \mathrm{Br}$, deca-lid 2:1, deca-lid 3:1, and deca-lid 4:1 show similar performance compared to toluene. Finally, PCSAFT was used to predict the distribution coefficients of FF and HMF in ternary LLE systems (DES + water + FF/HMF). PC-SAFT also predicted that deca-thy and thy-lid are the best extracting agents, for which the predictions were in quantitative agreement with the obtained experimental data.

\section{ASSOCIATED CONTENT}

S Supporting Information

The Supporting Information is available free of charge on the ACS Publications website at DOI: 10.1021/acs.iecr.8b06234.

Table S1, pure-component PC-SAFT parameters for DESs, water, FF, and HMF; Table S2, extraction coefficients of pure wt $\% \mathrm{HMF}+1 \mathrm{wt} \% \mathrm{FF}$ for different shaking times; Table S3, pure-component distribution coefficients obtained by extraction with 10 different DESs; Table S4, Kamlet-Taft parameters for the 10 different DESs and toluene and ethanol as reference; Tables S5 and S6, distribution coefficients obtained by extraction with four selected DESs from different starting solution; Table S7, distribution coefficient from FF in a ternary LLE system; and Table S8, distribution coefficient from HMF in a ternary LLE system (PDF)

\section{AUTHOR INFORMATION}

\section{Corresponding Authors}

*E-mail: maaike.kroon@ku.ac.ae. Phone: +971-26075317. Fax: +971-26075200.

*Regarding PC-SAFT: E-mail: christoph.held@tu-dortmund. de. Phone: +49 2317552086.

ORCID ${ }^{\circ}$

Maaike C. Kroon: 0000-0002-5985-986X

Funding

Chemelot InSciTe, project no. 00097, BB.03 (Horizontal project).

\section{Notes}

The authors declare no competing financial interest.

\section{ACKNOWLEDGMENTS}

This work was performed under the framework of Chemelot InSciTe-Horizontal project, with contributions from the European Regional Development Fund (ERDF) within the framework of OP-Zuid and with contributions from the province of Brabant and Limburg and the Dutch Ministry of Economic Affairs.

\section{REFERENCES}

(1) van Osch, D. J. G. P.; Kollau, L. J. B. M.; van den Bruinhorst, A.; Asikainen, S.; Rocha, M. M. A.; Kroon, M. C. Ionic liquids and deep eutectic solvents for lignocellulosic biomass fractionation. Phys. Chem. Chem. Phys. 2017, 19, 2636-2665. 
(2) Ordomsky, V.; van der Schaaf, J.; Schouten, J. C.; Nijhuis, T. A. Fructose Dehydration to 5-Hydroxymethylfurfural over Solid Acid Catalysts in a Biphasic System. ChemSusChem 2012, 5, 1812-1819.

(3) Perret, N.; Grigoropoulos, A.; Zanella, M.; Manning, T. D.; Claridge, J. B.; Rosseinsky, M. J. Catalytic Response and Stability of Nickel/Alumina for the Hydrogenation of 5-Hydroxymethylfurfural in Water. ChemSusChem 2016, 9, 521-531.

(4) Hu, L.; Zhao, G.; Hao, W.; Tang, X.; Sun, Y.; Lin, L.; Liu, S. Catalytic conversion of biomass-derived carbohydrates into fuels and chemicals via furanic aldehydes. RSC Adv. 2012, 2, 11184.

(5) Deng, Q.; Xu, J.; Han, P.; Pan, L.; Wang, I.; Zhang, X.; Zou, J. Efficient synthesis of high-density aviation biofuel via solvent-free aldol condensation of cyclic ketones and furanic aldehydes. Fuel Process. Technol. 2016, 148, 361-366.

(6) Guo, J.; Xu, G.; Han, Z.; Zhang, Y.; Fu, Y.; Guo, Q. Selective Conversion of Furfural to Cyclopentanone with CuZnAl Catalysts. ACS Sustainable Chem. Eng. 2014, 2, 2259-2266.

(7) Sievers, C.; Valenzuela-Olarte, M. B.; Marzialetti, T.; Musin, I.; Agrawal, P. K.; Jones, C. W. Ionic-Liquid-Phase Hydrolysis of Pine Wood. Ind. Eng. Chem. Res. 2009, 48, 1277-1286.

(8) Yan, K.; Wu, G.; La fleur, T.; Jarvis, C. Production, properties and catalytic hydrogenation of furfural to fuel additives and valueadded chemicals. Renewable Sustainable Energy Rev. 2014, 38, 663676.

(9) de Oliveira Vigier, K.; Chatel, G.; Jerome, F. Contribution of deep eutectic solvents for biomass processing: opportunities, challenges, and limitations. ChemCatChem 2015, 7, 1250-1260.

(10) Blumenthal, L. C.; Jens, C. M.; Ulbrich, J.; Schwering, F.; Langrehr, V.; Turek, T.; Kunz, U.; Leonhard, K.; Palkovits, R. Systematic Identification of Solvents Optimal for the Extraction of 5Hydroxymethylfurfural from Aqueous Reactive Solutions. ACS Sustainable Chem. Eng. 2016, 4, 228-235.

(11) Bhaumik, P.; Dhepe, P. L. Efficient, Stable, and Reusable Silicoaluminophosphate for the One-Pot Production of Furfural from Hemicellulose. ACS Catal. 2013, 3, 2299-2303.

(12) Sitthisa, S.; Resasco, D. E. Hydrodeoxygenation of Furfural Over Supported Metal Catalysts: A Comparative Study of $\mathrm{Cu}, \mathrm{Pd}$ and Ni. Catal. Lett. 2011, 141, 784-791.

(13) Croker, J. R.; Bowrey, R. G. Ind. Eng. Chem. Fundam. 1984, 23, 480-484.

(14) Deng, W.; Liu, M.; Zhang, Q.; Tan, X.; Wang, Y. Acid-catalysed direct transformation of cellulose into methyl glucosides in methanol at moderate temperatures. Chem. Commun. 2010, 46, 2668-2670.

(15) Rodriguez Rodriguez, N. Azeotrope Breaking Using Deep Eutectic Solvents; Technische Universiteit Eindhoven: Eindhoven, The Netherlands, 2016; pp 10-32.

(16) Gmehling, J.; Schedemann, A. Selection of Solvents or Solvent Mixtures for Liquid-Liquid Extraction Using Predictive Thermodynamic Models or Access to the Dortmund Data Bank. Ind. Eng. Chem. Res. 2014, 53, 17794-17805.

(17) Dietz, C. H. J. T.; Creemers, J. T.; Meuleman, M. A.; Held, C.; Sadowski, G.; van Sint Annaland, M.; Gallucci, F.; Kroon, M. C. Determination of the Total Vapor Pressure of Hydrophobic Deep Eutectic Solvents: Experiments and Perturbed-Chain Statistical Associating Fluid Theory Modeling. ACS Sustainable Chem. Eng. 2019, 7, 4047-4057.

(18) Abbott, A. P.; Capper, G.; Davies, D. L.; Rasheed, R. K.; Tambyrajah, V. Novel solvent properties of choline chloride/urea mixtures. Chem. Commun. 2003, 1, 70-71.

(19) Dai, Y.; van Spronsen, J.; Witkamp, G. J.; Verpoorte, R.; Choi, Y. H. Natural deep eutectic solvents as new potential media for green technology. Anal. Chim. Acta 2013, 766, 61-68.

(20) Zhang, Q.; de Oliveira Vigier, K.; Royer, S.; Jérôme, F. Deep eutectic solvents: syntheses, properties and applications. Chem. Soc. Rev. 2012, 41, 7108.

(21) van Osch, D. J. G. P.; Zubeir, L. F.; van den Bruinhorst, A.; Rocha, M. M. A.; Kroon, M. C. Hydrophobic deep eutectic solvents as water-immiscible extractants. Green Chem. 2015, 17, 4518.
(22) Zubeir, L. F.; Held, C.; Sadowski, G.; Kroon, M. C. PC-SAFT Modeling of $\mathrm{CO}_{2}$ Solubilities in Deep Eutectic Solvents. J. Phys. Chem. B 2016, 120, 2300-2310.

(23) Dietz, C. H. J. T.; van Osch, D. J. G. P.; Kroon, M. C.; Sadowski, G.; van Sint Annaland, M.; Gallucci, F.; Zubeir, L. F.; Held, C. PC-SAFT modeling of $\mathrm{CO}_{2}$ solubilities in hydrophobic deep eutectic solvents. Fluid Phase Equilib. 2017, 448, 94-98.

(24) San Roman, M. F.; Bringas, E.; Ibanez, R.; Ortiz, I. Liquid membrane technology: fundamentals and review of its applications. $J$. Chem. Technol. Biotechnol. 2010, 85, 2-10.

(25) Althuluth, M.; Overbeek, J. P.; van Wees, H. J.; Zubeir, L. F.; Haije, W. G.; Berrouk, A.; Peters, C. J.; Kroon, M. C. Natural gas purification using supported ionic liquid membrane. J. Membr. Sci. 2015, 484, 80-86.

(26) Dietz, C. H. J. T.; Erve, A.; Kroon, M.C.; van Sint Annaland, M.; Gallucci, F.; Held, C. Thermodynamic and solubility properties of hydrophobic deep eutectic solvents and solubility of water and HMF in them: Measurements and PC-SAFT modelling. Fluid Phase Equilib. 2019, DOI: 10.1016/i.fluid.2019.02.010.

(27) Gross, J.; Sadowski, G. Application of the Perturbed-Chain SAFT Equation of State to Associating Systems. Ind. Eng. Chem. Res. 2002, 41, 5510-5515.

(28) Gross, J.; Sadowski, G. Perturbed-Chain SAFT: An Equation of State Based on a Perturbation Theory for Chain Molecules. Ind. Eng. Chem. Res. 2001, 40, 1244-1260.

(29) Barker, J. A.; Henderson, D. Perturbation Theory and Equation of State for Fluids: The Square-Well Potential. J. Chem. Phys. 1967, 47, 2856-2861.

(30) Barker, J. A.; Henderson, D. Perturbation Theory and Equation of State for Fluids. II. A Successful Theory of Liquids. J. Chem. Phys. 1967, 47, 4714-4721.

(31) Warrag, S. E. E.; Pototzki, C.; Rodriguez, N. R.; van Sint Annaland, M.; Kroon, M. C.; Held, C.; Sadowski, G.; Peters, C. J. Oil desulfurization using deep eutectic solvents as sustainable and economical extractants via liquid-liquid extraction: Experimental and PC-SAFT predictions. Fluid Phase Equilib. 2018, 467, 33-44.

(32) van Osch, D.; Dietz, C. H. J. T.; van Spronsen, J.; Kroon, M.; Gallucci, F.; van Sint Annaland, M.; Tuinier, R. A Search for Natural Hydrophobic Deep Eutectic Solvents Based on Natural Components. ACS Sustainable Chem. Eng. 2019, 7, 2933.

(33) Sindermann, E.; Holbach, A.; de Haan, A.; Kockmann, N. Single stage and countercurrent extraction of 5-hydroxymethylfurfural from aqueous phase systems. Chem. Eng. J. 2016, 283, 251-259.

(34) Mohammad, S.; Held, C.; Altuntepe, E.; Köse, T.u.; Sadowski, G. Influence of Salts on the Partitioning of 5-Hydroxymethylfurfural in Water/MIBK. J. Phys. Chem. B 2016, 120, 3797-3808. 